SECTION 26. Radio-technique. Electronics. Telecommunications.

\author{
Vladislav Sergiyovych Oliynyk \\ student \\ Kyiv Electromechanical College, Ukraine \\ oleinik-vlad@yandex.ua
}

\title{
METHOD FOR CONTROLLING THE STATE OF POWER LINES
}

Abstract: The article suggests a method for controlling the state of power lines by monitoring the electricity losses in certain segments of power lines. This method is significantly different from the existing ones because monitoring of the entire length of power lines is performed at a single point. This method can be used to control such power line parameters as wire cross-section, geometric mean distance between the line wires, outer wire diameter, and other parameters that affect the electricity losses. The article provides an example of a mathematical model and a block diagram for this method.

Key words: condition monitoring of power lines, precision system of protection of power lines.

High-voltage overhead power transmission lines are the most accident-sensitive element in an integrated technological chain of electricity consumers. Therefore, controlling the state of power lines is a pressing issue. It would provide an opportunity to timely react on depreciation of the lines in order to prevent further damage and, therefore, increased energy losses. According to the European Union Directive 2012/27/EU of 25 October 2012 on energy efficiency [1] and the program of the European Investment Bank on innovations in energy efficiency solutions [2], the problem of implementation of new technologies in order to improve energy efficiency is rather urgent.

A well-known method for controlling the technical state of power lines [3] is based on the control performed by the electro-optical equipment (thermal imaging). The disadvantage of this method is that only a few elements of a power network are controlled (transformers, insulators, disconnectors) due to the necessity of installing surveillance cameras on every monitored object.

A well-known device for remote control of the state of overhead power transmission lines [4] monitors the following power lines parameters: temperature, current, wire tension, static and dynamic parameters of the position of the wire in the air. The disadvantage of this device is that it only shows the parameters of the section of the line on which it is mounted.

A well-known method of power lines laser mapping [5] is based on the monitoring that is carried out by a laser air mapping scan along the line. The disadvantage of this method is difficulty of implementation and a lack of controlled parameters.

The method for determining the local losses in power transmission lines is based on determining the voltage drop in a separate part of the lines. It requires knowing a value of the length of the transmission line 1, which connects the two electricity sources $G 1$ and $G 2$ (Figure 1).

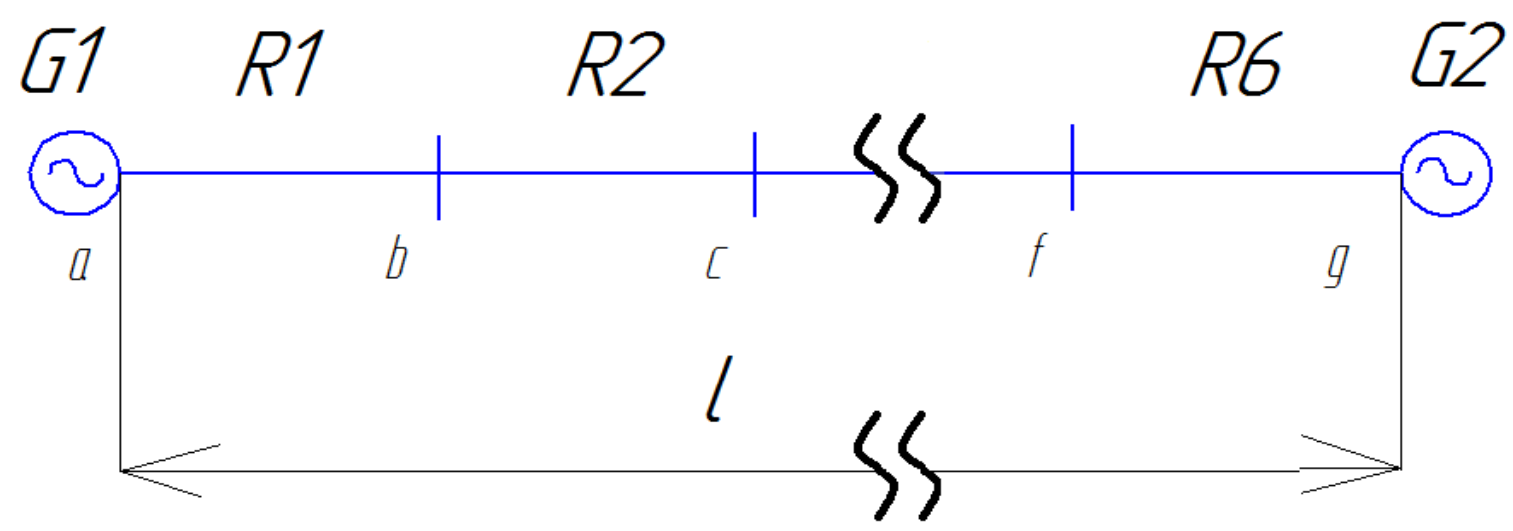

Figure 1 - Schematic diagram of a power line 
Depending on the accuracy of determining local losses the length of the line is divided into equal length segments. The resistance of each segment, such as $a b$, is calculated by the formula [6]:

$$
R 1=\frac{p \cdot\left(l 1 \cdot 10^{3}\right)}{F \cdot \gamma}
$$

$p$ - resistivity of the wire material, $\frac{\mathrm{Ohm} \cdot \mathrm{mm^{2 }}}{m}$

where $l 1 \cdot 10^{3}-$ length of the power line segment, $\mathrm{m}$;

$l 1$ - length of the power line segment, $\mathrm{km}$;

$F$ - rated wire cross-section, $\mathrm{mm}^{2}$;

$\gamma$-conductivity of the wire material, $\frac{\mathrm{m}}{\mathrm{Ohm} \cdot \mathrm{mm}^{2}}$.

Inductive reactance $X 1, a b \mathrm{Ohm}$ area of a three-phase line with nonferrous metal wires at an alternating current frequency of $50 \mathrm{~Hz}$ [6]:

$$
x_{0}=\left(0,145 \lg \frac{\text { Dmean }}{R}+0,0157 \mu\right) \cdot l 1,
$$

where $0,145 \lg \frac{\text { Dmean }}{R}$ - inductive reactance that depends on the magnetic field outside the wire;

Dmean - geometric mean distance between the line wires, $\mathrm{mm}$;

$\mathrm{R}$ - wire radius, $\mathrm{mm}$;

$0.0157 \mu$ - internal inductive reactance, Ohm;

$\mu$-relative magnetic permeability of the wire.

As shown in the formulas (1) and (2) p, Dmean, $d$, and $F$ are standard parameters, whereas $l 1$ is set independently. Thus the value of the impedance for this power line segment is nominal. The growth of this value leads to higher losses in this part of the line which are caused by abnormal functioning of the elements of the power lines.

Below there is a simplified mathematical model of a calculation that does not take into account the peculiarities of voltage wave propagation in a power line (e.g. wave refraction and reflection) [7], which is necessary in real-life environment.

Determination of local losses in power lines is generally performed in the following order:

1. Source $G 2$ (Figure 1) sends a voltage pulse $U$ into the line. This pulse will reach source $G 1$ at value

$$
U k=U-\Delta U, \mathrm{~V}
$$

Where $U k$ - value of the voltage pulse that reached $G 1, \mathrm{~V}$;

$\Delta U$ - voltage drop along all the length of the power line, $\mathrm{V}$.

2. The formula (3) calculates the voltage drop in the power line:

$$
\Delta U=U-U k, \mathrm{~V}
$$


3. Source $G 2$ sends a voltage pulse $U$ into the line. After a certain period of time $T 1, \mathrm{sec}$, calculated by the formula (5), source $G 1$ sends a voltage pulse at a value calculated by the formula (6), so that the pulse from the source $G 1$ and the pulse from the source $G 2$ meet at point $b$.

$$
T 1=\frac{l-2 l 1}{c}, \text { sec }
$$

Where $l$ - length of the whole segment of the power line, $\mathrm{km}$; $c$ - light speed, $300000 \mathrm{~km} / \mathrm{sec}$.

where $U^{`}-$ value of the first pulse from source $G 1$, V.

$$
U=U-2 \Delta U, \mathrm{~V}
$$

Pulse $U^{\prime}$ will reach point $b$ with voltage calculated by the formula (7):

$$
U^{`} b=U^{`}-\Delta U 1, \mathrm{~V}
$$

Where $\Delta U 1$ - value of the voltage drop in segment $a b, \mathrm{~V}$.

The value of the pulse $U$ at point $b$ is calculated by the formula (8):

$$
U b=U-(\Delta U+\Delta U 1), \mathrm{V}
$$

Pulse $U^{`} b$, meeting pulse $U b$ at point $b$, influences it as shown in the formula (9):

$$
U b^{`}=U b-U^{`} b, \mathrm{~V}
$$

This pulse will reach source $G 1$ at value

$$
U k 1=U b-\Delta U 1, \mathrm{~V}
$$

4. The formula (11) calculates the voltage drop in the segment $l 1$ :

$$
\Delta U 1=U-U-\Delta U, \mathrm{~V}
$$

5. The voltage drop calculation in the segment $l 2$ is performed in the similar way, however the final value is calculated with the formula (12):

$$
\Delta U 2=U-U-\Delta U-\Delta U 1, \mathrm{~V}
$$
in figure 2:

The block diagram of the actuating mechanism utilizing this method is demonstrated 


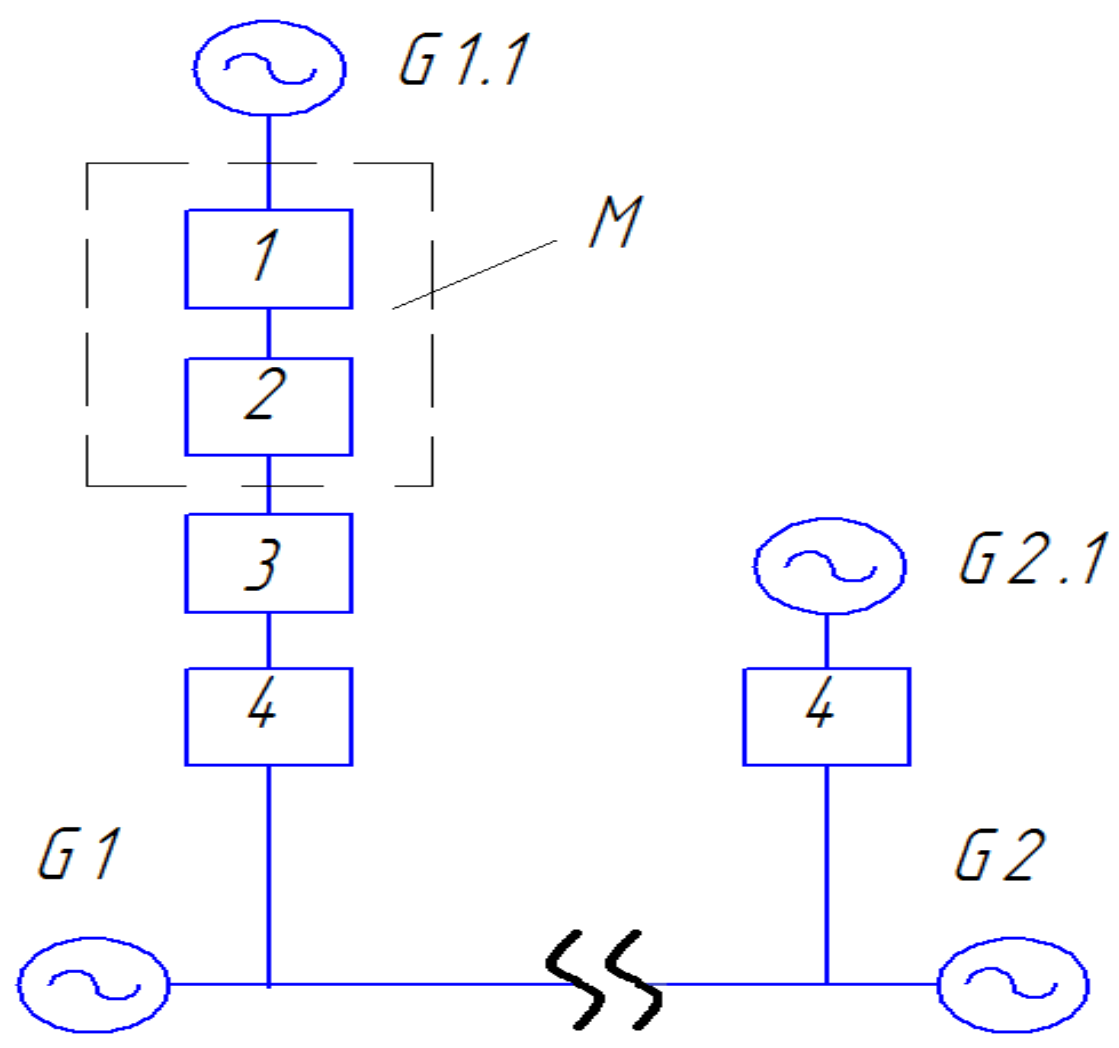

Figure 2 - Block diagram of the actuating mechanism

The actuating mechanism consists of the following units which are connected in the following order:

1 - logical unit. Reacts on changes of electrical parameters in the line. Controls: $U k$, $\Delta U$. Depending on the values of the controlled parameters adjusts the value $U$ '. Depending on the stage of the calculation and on the determining accuracy of the point of electricity losses adjusts the parameter $T$.

2 - measuring unit. Measures the value of the parameter $U k$.

The unit 1 and the unit 2 make up a microprocessor unit $M$.

3 - transformer. Is used for increasing the pulse $U^{`}$ and decreasing the pulse $U k$.

4 - frequency filter.

The actuating mechanism is necessary only on one side of the power line, whereas the other side has source $G 2.1$ and frequency filter 4.

In real-life environment this block diagram of an actuating mechanism can work in the following mode: $G 1$ and $G 2$ are sources of $50 \mathrm{~Hz}$ alternating current with $35 \mathrm{kV}$ voltage; $G 1.1$ - source of direct current with $220 \mathrm{~V}$ voltage; unit 3 - transformer $0.2 / 10 \mathrm{kV}$; unit 4 $100 \mathrm{~Hz}$ frequency filter; $G 2.1$ - source of $100 \mathrm{~Hz}$ alternating current with $10 \mathrm{kV}$ voltage.

As shown in formulae (1), (2) this method of determining local losses provides a timely response on changes of such power line parameters as nominal wire cross-section, geometric mean distance between the line wires, outer wire diameter, and other unforeseen factors that can cause electricity losses in a power line.

\section{Conclusion}


1. This article suggests a method for remote evaluation of local losses in power lines which provides an opportunity to timely react on any deviations in the functioning of power lines.

2. The article provides a mathematical model for calculating voltage losses in areas of power lines.

3. The article suggests a block diagram of the actuating mechanism for this method.

\section{References:}

1. Directive 2012/27/EU of the European parliament and of the council "on energy, efficiency, amending Directives 2009/125/EC and 2010/30EU and repealing Directives 2004/8/EC and 2006/32/EC" of 25 October 2012. - Published 2012-11-14. - 56 p.

2. European Investment Bank: Supporting sustainable, competitive and secure energy in Europe. - Published 2013-05-28. - 8 p.

3. Электронно-оптическое оборудование при контроле технического состояния элементов сетей и подстанций на рабочем напряжении/ Оборудование для неразрушающего контроля. - URL: http://www.panatest.ru/articles/art4.asp - (Date of access: 15.03.2014).

4. Russian patent №2222858.

5. Современные технологии мониторинга воздушных электросетей ЛЭП / Control Engineering. URL: $\quad$ http://controlengrussia.com/otraslevye-resheniya/sovremenny-e-tehnologiimonitoringa-vozdushny-h-e-lektrosetej-le-p/ - (Date of access: 15.03.2014).

6. Активные и индуктивные сопротивления линий / Территория электротехнической информации. - URL: http://www.websor.ru/aktivnje i induktivnje soprotivleniya.html - (Date of access: 15.03.2014).

7. В.П. Ларионов, В.В. Базуткин. Техника высоких напряжений. - Москва; Энергоиздат, 1982 - 296 с. 